\title{
Technical Note: A novel rocket-based in situ collection technique for mesospheric and stratospheric aerosol particles
}

\author{
W. Reid ${ }^{1}$, P. Achtert ${ }^{2}$, N. Ivchenko ${ }^{1}$, P. Magnusson ${ }^{1}$, T. Kuremyr ${ }^{1}$, V. Shepenkov ${ }^{3}$, and G. Tibert ${ }^{3}$ \\ ${ }^{1}$ School of Electrical Engineering, Royal Institute of Technology (KTH), Stockholm, Sweden \\ ${ }^{2}$ Department of Meteorology, Stockholm University, Stockholm, Sweden \\ ${ }^{3}$ Department of Mechanics, Royal Institute of Technology (KTH), Stockholm, Sweden
}

Correspondence to: N. Ivchenko (nickolay@kth.se)

Received: 27 September 2012 - Published in Atmos. Meas. Tech. Discuss.: 5 November 2012

Revised: 31 January 2013 - Accepted: 1 March 2013 - Published: 19 March 2013

\begin{abstract}
A technique for collecting aerosol particles between altitudes of 17 and $85 \mathrm{~km}$ is described. Spin-stabilized collection probes are ejected from a sounding rocket allowing for multi-point measurements. Each probe is equipped with 110 collection samples that are $3 \mathrm{~mm}$ in diameter. The collection samples are one of three types: standard transmission electron microscopy carbon grids, glass fibre filter paper or silicone gel. Collection samples are exposed over a $50 \mathrm{~m}$ to $5 \mathrm{~km}$ height range with a total of 45 separate ranges. Postflight electron microscopy will give size-resolved information on particle number, shape and elemental composition. Each collection probe is equipped with a suite of sensors to capture the probe's status during the fall. Parachute recovery systems along with GPS-based localization will ensure that each probe can be located and recovered for post-flight analysis.
\end{abstract}

\section{Introduction}

The characterization of middle-atmospheric aerosols and related processes are of primary importance to investigate their influence on climate variability. The stratospheric aerosol is dominated by sub-micrometre hydrate sulphuric acid droplets which scatter incident sunlight. Sulphuric acid droplets are formed through oxidation of gases containing sulphur and sulphur dioxide (Hamill et al., 1997). The stratospheric aerosol layer extends from the tropopause to about $30 \mathrm{~km}$ altitude and is strongly influenced by the input of large volcanic eruptions (Bourassa et al., 2012, and Solomon et al., 2011).
Information about the size range and the concentration of stratospheric aerosols together with their vertical distribution was first obtained from balloon-borne impactor measurements in the late 1950s (Junge et al., 1961). Long-term measurements using balloon-borne particle counters (Deshler et al., 2003; Hofmann, 1990; Hofmann and Rosen, 1980; Hofmann et al., 1975) and lidar (DeFoor et al., 1992; Osborn et al., 1995; Jager, 2005) at a limited number of ground sites began in the early 1970s. Satellite remote sensing observations have been carried out since the late 1970s (e.g. Stratospheric Aerosol Measurements, SAM, II from 1979 to 1991 Pepin et al., 1997; Poole and Pitts, 1994; Stratospheric Aerosol and Gas Experiment, SAGE, from 19791981; SAGE II from 1984 to 2005 McCormick et al., 1979; and SAGE III from 2001 to present Thomason et al., 2007).

The upper-mesosphere aerosol is dominated by meteoric material that enters the earth's atmosphere, ablates, and forms nanometre-sized aerosol particles through chemical conversion, re-condensation, and coagulation. First in situ measurements of meteoric material in the mesosphere were conducted in the 1960s (Soberman and Hemenway, 1965; Blanchard et al., 1968; Farlow, 1968; Fechtig and Feuerstein, 1970). These particles are important for middle-atmospheric processes, such as noctilucent clouds (NLCs), polar mesospheric summer echoes (PMSEs), metal layers, and the heterogeneous chemistry that controls the budget of key species like water vapour (Turco et al., 1982; Summers and Siskind, 1999; Plane, 2000; Megner et al., 2008).

Information on the spatial extent and abundance of NLCs and PMSEs, as well as the size and composition of NLC particles, has been continuously monitored by satellite-based 
instruments (e.g. DeLand et al., 2006; Pérot et al., 2010) and ground-based instruments since the late 1970s (e.g. Bremer et al., 2009; Kaifler et al., 2011). On the other hand, the microphysical properties of meteoric-smoke particles are still poorly understood. This lack of knowledge is due to the complications involved with in situ measurements at mesospheric altitudes that can only be reached by sounding rockets (Farlow et al., 1970; Havnes et al., 1996; Goldberg et al., 2001; Smiley et al., 2002; Rapp et al., 2005; Lynch et al., 2005; Hedin et al., 2007b). Furthermore, the detection of nanometre-sized particles is constrained by the shock wave in front of the rocket, which may prevent small particles from reaching the detector (Hedin et al., 2007a) and by contamination from the rocket itself. Hence, reliable in situ aerosol measurements in the middle atmosphere are rare. Note that balloon-borne in situ measurements only reach heights of up to $40 \mathrm{~km}$ while rocket-borne in situ measurements only cover the upper mesosphere. Therefore, a new method for in situ sampling of middle-atmospheric aerosol particles and successive characterization of their chemical composition is needed.

This paper presents a novel instrument which has been developed as a proof of concept of an in situ aerosol collection technique covering the mesosphere and stratosphere. It will be tested in the framework of the Rocket deployed Atmospheric probes conducting Independent measurements in Northern Sweden (RAIN) experiment, which has been realized through participation in the REXUS/BEXUS program, a bi-lateral cooperation between the Swedish National Space Board (SNSB) and the German Aerospace Center (DLR). RAIN is part of the REXUS-11 sounding rocket, whose launch is currently scheduled for late 2012. The REXUS11 is powered by an Improved Orion solid fuel motor. The rocket is unguided and reaches an altitude of $85 \mathrm{~km}$.

This paper begins with an overview of the instrument design and the flight timeline in Sect. 2. Section 3 describes the design and testing of the aerosol collection experiment (ACE). Information regarding the electronics is summarized in Sect. 4, and conclusions are provided in Sect. 5.

\section{Experiment outline}

The experiment consists of two main sections: a rocket mounted unit (RMU) shown in Fig. 1 and the two collection probes or free falling units (FFUs) shown in Fig. 2.

The RMU is a standard REXUS module (EuroLaunch, 2010) containing an FFU ejection system. The FFU ejection system is a spring-based mechanism constrained by a steel cable guided around the outside of the RMU. Ejection of the FFUs occurs when a pyro-cutter cuts the cable. Both FFUs are symmetrically ejected in the spin plane at $5 \mathrm{~m} \mathrm{~s}^{-1}$.

Each FFU has a cylindrical shape with a height of $93 \mathrm{~mm}$ and a diameter of $116 \mathrm{~mm}$. It is composed of a parachute recovery system, an electronics system and an aerosol

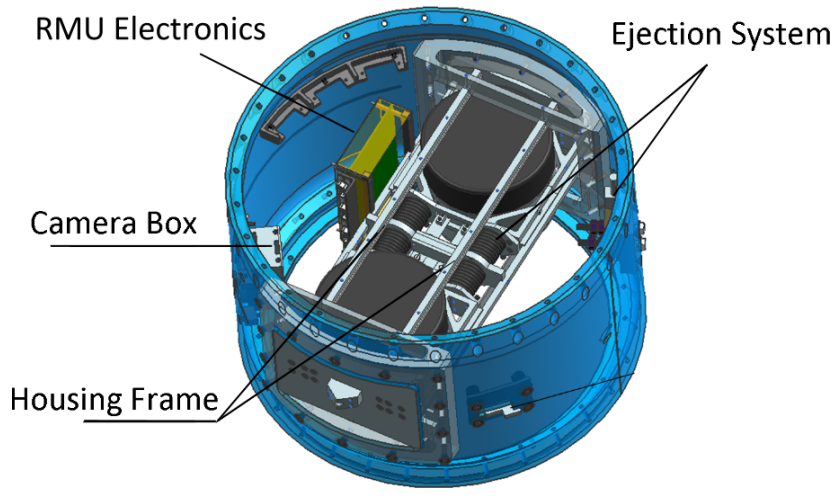

Fig. 1. The rocket mounted unit (RMU). A modified REXUS rocket cylinder that houses the free falling units (FFUs), the FFU ejection system and the RMU electronics. The ejection system pushes the FFUs out the sides of the rocket $67 \mathrm{~s}$ after launch. The electronics are used to control communication between the FFUs, the RMU and the REXUS service module. In addition a camera is mounted on the inner wall of the RMU looking outwards to capture footage of the REXUS flight.

collection experiment (ACE). The FFU's main structure is made of aluminium with an unsealed surface. A parachute is held inside the FFU hat on top of the FFU, which is released by a spring-loaded parachute deployment mechanism. The electronics system is used to power, control and monitor the FFU and is elaborated on in Sect. 4. The ACE is responsible for collecting aerosol particles and is discussed in Sect. 3.

The experiment timeline starts $67 \mathrm{~s}$ after launch at an altitude of approximately $63 \mathrm{~km}$ when the FFUs are ejected from the RMU. Given that the rocket is spinning at $4 \mathrm{~Hz}$ at ejection, the FFUs are ejected spinning at approximately $2 \mathrm{~Hz}$ about their longitudinal axes. This rotation results in angular momentum that stabilizes each FFU. The FFUs continue to rise to an apogee of approximately $85 \mathrm{~km}, 150 \mathrm{~s}$ after launch. At apogee, each FFU will activate its ACE. The ACE is deactivated after the FFU has fallen to an altitude of approximately $17 \mathrm{~km}, 285 \mathrm{~s}$ after launch. At $6 \mathrm{~km}$ or $360 \mathrm{~s}$ after launch, the FFU will deploy its parachute. An alive signal along with the FFU's GPS position will begin to be broadcast at this point. FFU touchdown will occur approximately $1200 \mathrm{~s}$ after launch. The FFU will continue to transmit its position until the FFUs are recovered by a helicopter recovery crew or its battery expires approximately $24 \mathrm{~h}$ after launch. Figure 3 shows a flight timeline diagram that presents the major milestones of the experiment's flight.

The returned FFUs will have their aerosol collection samples analysed using scanning electron microscopy (SEM) and transmission electron microscopy (TEM). SEM gives information about size, form, and composition of the collected particles. Electron microscopy is a method used to investigate these parameters down to a particle diameter of $15 \mathrm{~nm}$ (Kandler et al., 2007; Capannelli et al., 2011). SEM used for the investigation of aerosol particles has been used for more 


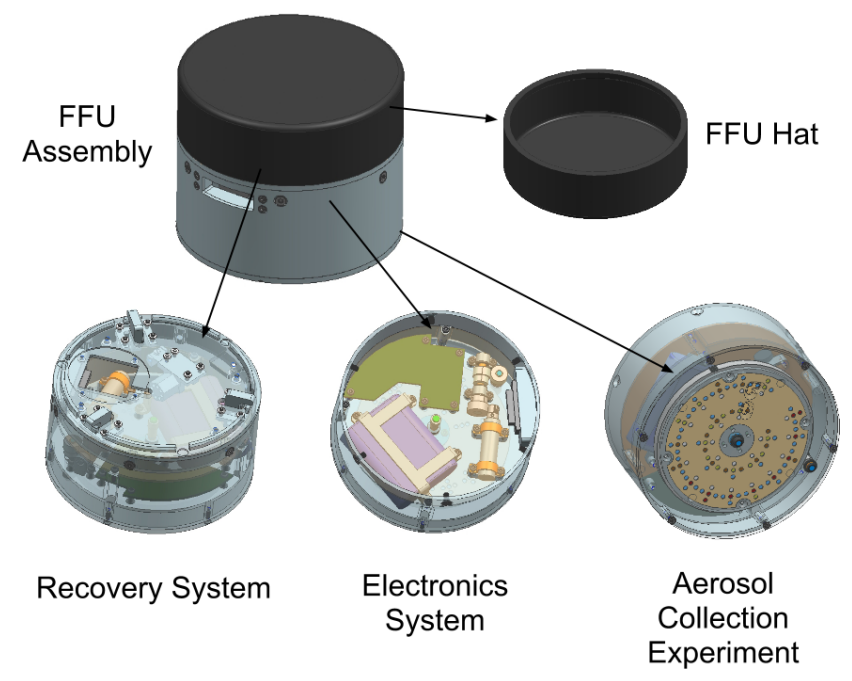

Fig. 2. The FFU is divided into four parts. The FFU hat holds a parachute inside it. The hat and parachute are deployed by the recovery system when the FFU falls past an altitude of $6 \mathrm{~km}$. The electronics system is responsible for running the collection experiment, recording sensor readings and transmitting localization signals. The aerosol collection experiment exposes $3 \mathrm{~mm}$ diameter collection samples to the passing atmosphere between altitudes of 17 and $85 \mathrm{~km}$.

than $50 \mathrm{yr}$ (e.g. Parungo and Nagamoto, 1986; Sielicki et al., 2011). For the analysis of smaller particles $(<20 \mathrm{~nm})$, a TEM with energy-dispersive $\mathrm{X}$-ray spectrometer will be used. The TEM analysis can provide number, size, and shape of the detected particle as well as the elemental composition.

\section{Aerosol collection experiment}

The aerosol collection experiment (ACE) is located in the base of an FFU as shown in Fig. 2. The ACE system includes a group of aerosol collection samples held inside a collection plate assembly. During the FFU's fall, aerosol particles are captured as they collide with collection samples that are exposed to the passing atmosphere. Exposure of individual collection samples is controlled by a stepper motor powered drive system shown in Fig. 4. The drive system rotates the collection plate containing the collection samples past an arrangement of exposure windows in the base of the FFU. The position of the collection plate is monitored by a magnetic angular encoder. This way, each collection sample's angular position on the plate can be matched with a time and altitude range of sampling. An FFU's altitude is extracted from GPS data collected throughout the FFU's fall. Timing data are provided by the internal FFU clock.

\subsection{Assembly}

The collection plate assembly has three components: the aerosol collection sample holders, the collection plate lid,

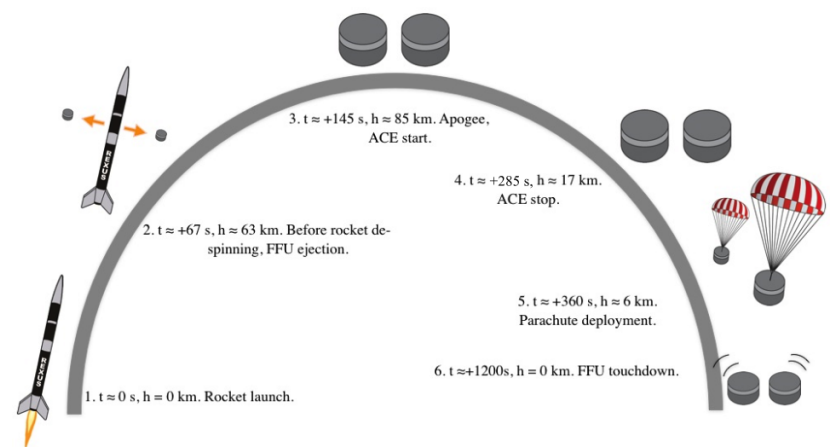

Fig. 3. The major milestones of the RAIN experiment include launch, ejection of the FFUs from the rocket, aerosol collection experiment stop, parachute deployment and localization system initiation.

and the collection plate. An exploded view of the assembly is shown in Fig. 5.

There are a total of 110 aerosol collection samples inside an FFU. Each sample is $3 \mathrm{~mm}$ in diameter and is made from one of three separate materials. There are 44 copper grid coated carbon film collection samples that are typically used in transmission electron microscopy (TEM) applications. Each of these samples is $0.01 \mathrm{~mm}$ thick. There are three sub-types of these samples: 18 Formvar/carbon 400mesh samples with a grid hole size of $42 \mu \mathrm{m}, 16$ ultrathin carbon type-A, 400-mesh samples and 10 ultrathin carbon film on holey carbon support film, 400-mesh. These TEM grids are manufactured by Ted Pella, Inc., USA. TEM grids were previously used in aerosol collection experiments on stratospheric balloons (e.g. Bigg et al., 1971; Testa et al., 1990; Corte et al., 2012) and sounding rockets (Gumbel, 2007). The sticking probability for nanometre particles accelerated to $1 \mathrm{~km} \mathrm{~s}^{-1}$ on TEM grids was tested by Reissaus et al. (2006). Furthermore, Reissaus et al. (2006) found that nanoparticles (composed of $\mathrm{Al}_{2} \mathrm{O}_{3}$ and carbon), both as single particles and fractal agglomerates, do stick after impacts at high velocities with moderate to high efficiency $(10-90 \%)$ to these targets. An additional 22 collection samples are $0.3 \mathrm{~mm}$ thick pieces of glass fibre filter (PreSep TCLP Filter, glass fibre, $0.5 \mu \mathrm{m}$, Advance Scientific and Chemical, Inc., USA). The remaining 44 collection samples are $20 \mu \mathrm{L}$ drops of silicone gel (NuSil Silicone Technology, USA, gel-8100).

In each height bin a TEM grid is exposed to the atmosphere. Further, in every height bin different sample materials are included to test them under atmospheric conditions. The various aerosol collection samples have been chosen based on the size of particles they are expected to collect. The ultrathin carbon film on holey carbon grids (red material type in Fig. 6) are expected to collect mesospheric particles with diameters in the range between 5 and $20 \mathrm{~nm}$. They are therefore positioned on the collection plate so that they will be exposed while the FFU is falling through the mesosphere, 


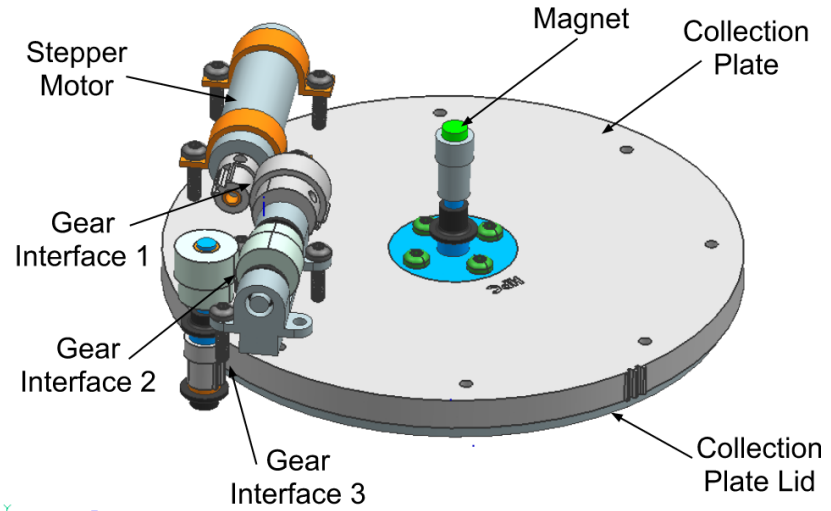

Fig. 4. The aerosol collection experiment (ACE) is composed of the collection plate assembly, which is rotated in the base of the FFU to incrementally expose aerosol collection samples to the passing atmosphere. The stepper motor drives the collection plate via the gear system. A magnet on the central shaft of the collection plate assembly is used with a magnetic angular encoder to track the angular position of the ACE.

where nanometre-sized meteoric smoke particles may be collected. The remaining copper grid coated carbon film samples are expected to collect particles with sizes on the order of tens to hundreds of nanometres. The glass fibre filters and gels are expected to collect particles up to micrometre sizes.

The arrangement of the collection samples inside a collection plate assembly is shown in Fig. 6. The row 1 and 6 collection samples are not exposed during the fall. These are control samples that will be analysed to check for sample contamination. Rows 2, 3, 4 and 5 all house samples that will be exposed.

Each collection sample is placed inside a $3 \mathrm{~mm}$ diameter bed cut into the surface of a $5 \mathrm{~mm}$ high and $12 \mathrm{~mm}$ diameter collection sample holder. The beds are arranged in a pattern that matches the shape of the exposure windows in the base of the FFU. The holder has been designed to have the same dimensions as a sample holder typically used in SEM. To observe the collection samples during post-flight analysis, the sample holder is taken out of the collection plate and put directly into the microscope, preventing possible contamination.

The collection plate shown in Fig. 5 is a modified $90 \mathrm{~mm}$ diameter and $5 \mathrm{~mm}$ tall spur gear. The collection plate has 22 beds that are $3 \mathrm{~mm}$ high and $12 \mathrm{~mm}$ in diameter cut out of its bottom surface to house 22 collection sample holders. The collection plate is attached to a central shaft about which the plate rotates. A collection plate lid is fastened to the collection plate after the sample holders have been loaded. The lid, shown in Fig. 5, has a mirror pattern of $2 \mathrm{~mm}$ high and $12 \mathrm{~mm}$ diameter beds to the collection plate, which the protruding sections of the collection sample holders rest in, thereby securing the holders in the collection plate assembly.

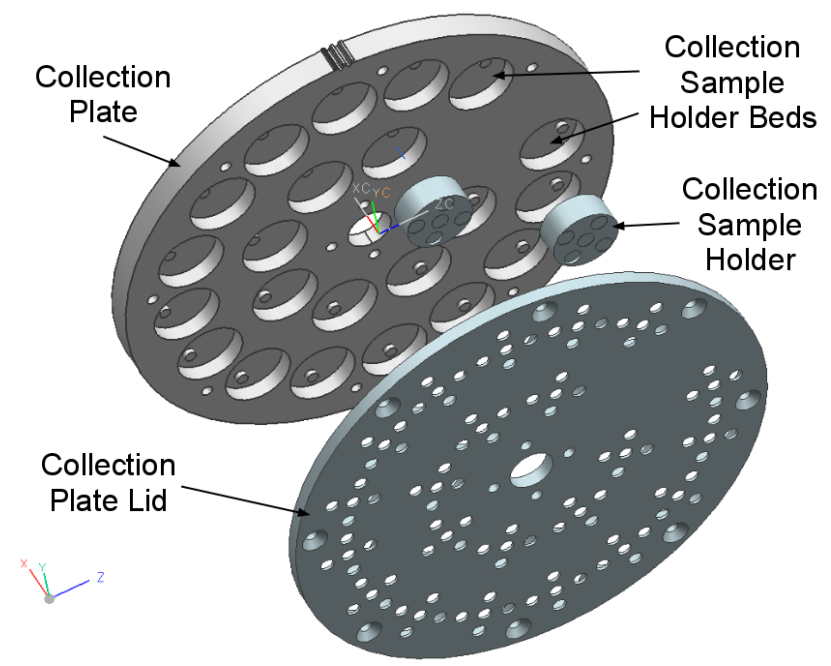

Fig. 5. The collection plate assembly is composed of a collection plate, which holds 22 collection sample holders inside its collection sample holder beds. The collection plate lid is fastened to the collection plate to hold the collection sample holders in place.

Below the collection plate assembly is the FFU baseplate. The collection samples are exposed to the passing atmosphere through two exposure windows in the plate shown in Fig. 7. The outer window exposes the set of collection sample holders in rows 2 and 3, while the inner window exposes samples in rows 4 and 5 . The exposure windows have a minimum opening width of $3 \mathrm{~mm}$, allowing for a whole aerosol collection sample to be exposed. At any one time, one, three or five collection sample holders are exposed in the course of the rotation of the collection plate.

To ensure that the collection samples are not contaminated inside the structure, a seal is created between the collection plate and the baseplate using Teflon-coated glass fibre covers. One cover is glued onto the top surface of the baseplate while the other is glued to the bottom surface of the collection plate assembly. The two surfaces are pressed together by a spring washer positioned on the central shaft between the top of the collection plate and the ceiling of the FFU's ACE compartment.

To prevent contamination of the aerosol collection samples, all structural components used in the FFUs are cleaned in an ultrasonic bath and then cleaned in isopropyl alcohol. The integration of the ACE and final assembly of the FFUs is performed in a clean room. The FFUs are placed in sealable bags for transportation and handling before final assembly with the RMU.

\subsection{Actuation and control}

The ACE is driven by a Faulhaber AM1020 stepper motor with a Faulhaber 10/1 256:1 gearhead. The motor/gearhead is geared down further by a 216:5 gear system resulting 


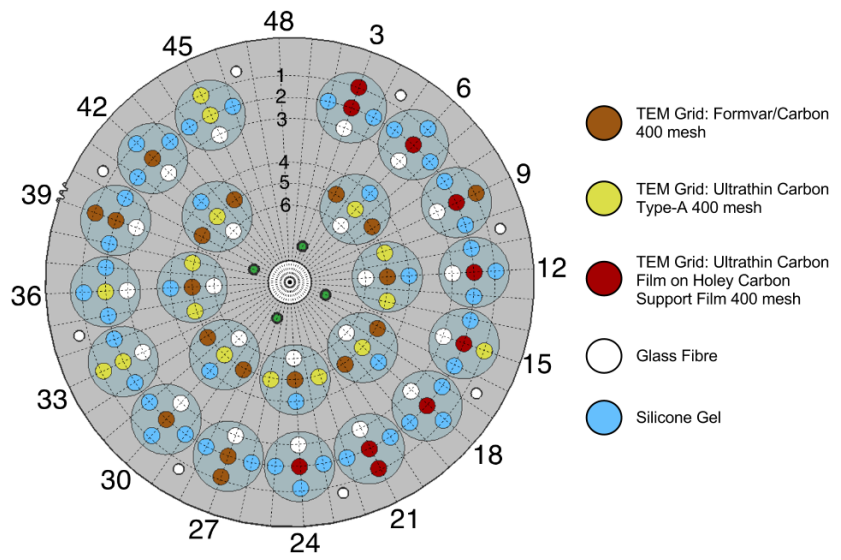

Fig. 6. The coordinate system for the positioning of each of the aerosol collection samples. A total of 6 rows and 48 columns are used to locate specific collection samples. The columns are on the radial lines originating at the centre of the collection plate, and the rows are the concentric circles. Each collection sample is colour coded to indicate the sample's material type.

in a total gear ratio of $55296: 5$. The motor is operated at $4740 \mathrm{rpm}$ corresponding to a collection plate rotation rate of $0.43 \mathrm{rpm}$.

A control procedure rotates the stepper motor at a continuous speed, checks for stalling and attempts to recover rotation in case of a stall. The magnetic angular encoder above the collection plate's central shaft tracks a magnet on the shaft tip. If the magnet ceases to rotate for $0.1 \mathrm{~s}$ during the collection phase of the experiment, it is assumed that the motor has stalled. After a $0.1 \mathrm{~s}$ delay the motor is restarted with maximum current for $5 \mathrm{~s}$, after which the motor current is returned to nominal levels to avoid motor winding burnout. The maximum winding current results in a $50 \%$ increase in nominal motor torque. When the angular encoder measures that the collection plate has been rotated a full $360^{\circ}$ after $140 \mathrm{~s}$ of rotation, the collection phase has come to an end and the motor is deactivated.

\subsection{Collection regime}

The scientific goal of RAIN is to collect aerosol particles over a large altitude range, and to be able to compare the composition of aerosol particles at different heights between $17 \mathrm{~km}$ and $85 \mathrm{~km}$. The height range studied is divided into 45 separate ranges, given that 45 out of the 48 columns shown in Fig. 6 contain collection samples. The remaining three columns expose sections of the collection plate without collection samples before the FFU starts to fall and after the collection regime is complete.

The time required for the FFU to fall through the entire height range of interest is approximately $140 \mathrm{~s}$. Operating the motor at $4740 \mathrm{rpm}$ for this period of time allows for each collection plate column to be passed by the exposure windows.

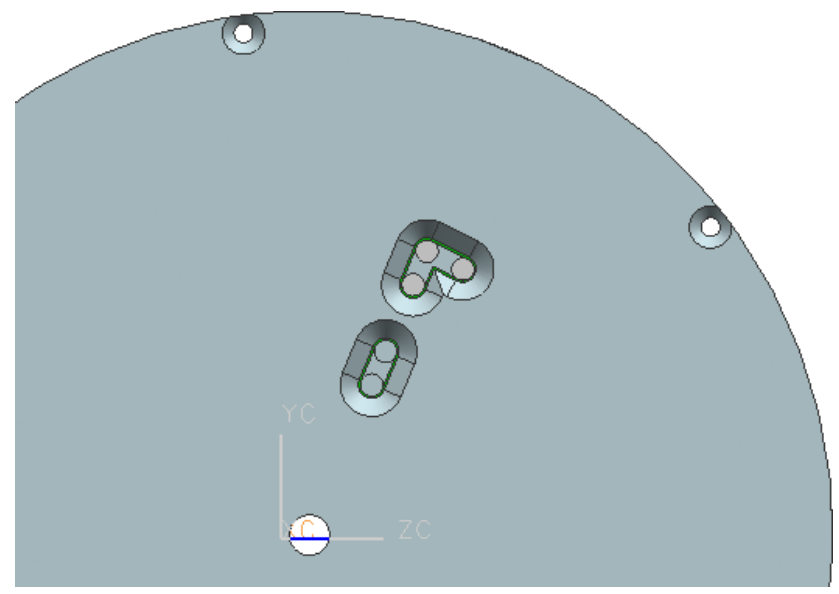

Fig. 7. Two exposure windows in the baseplate allow for aerosol collection samples to be exposed to the passing atmosphere during the FFU's fall. Collection samples are incrementally passed by these windows throughout the fall. A maximum of three and two collection samples can be exposed through the top and bottom windows respectively at any one time.

Figure 8 shows the resulting height ranges that each column in row 2 is exposed to during the fall.

Each collection sample row differs in their respective sample exposure times based on the size of the exposure window and the sample's radial distance from the centre of the collection plate. Table 1 shows how long a single sample in a given row is exposed for. During post-flight analysis plate angular position is matched with GPS altitude data.

\subsection{Contamination testing}

Two different tests were conducted to verify the ACE seal prevents contamination. First, a laboratory test was performed to ensure that no contamination was caused by the instrument itself. In a second test under atmospheric conditions, parts of the sample holders were exposed to the environment. The used target materials were checked by SEM (JEOL JSM-7401F) before every test run where images were taken from selected sample quadrants for a later comparison to post-sampling conditions.

For the first test, a sample holder loaded with one TEM grid, one glass fibre filter, and one silicone gel was loaded into the collection plate and one full plate rotation was performed. SEM analysis was performed directly after the test. While the analysis of the TEM grid and the silicone gel showed no signs of contamination, two kinds of particles were found on the glass fibre filter. Analysis of the latter filter revealed that one particle was a $200 \mu \mathrm{m}$ long fibre most likely originating from the Teflon sealing between the aerosol collection plate and the baseplate. The other particles were aluminium based between 0.15 and $0.25 \mu \mathrm{m}$ in diameter. These kind of particles were most likely from the FFU aluminium 
Table 1. The aerosol collection sample exposure times associated with each row of samples on the collection plate as shown in Fig. 6. Collection samples are exposed as the collection plate is rotated past the exposure windows in the base of the FFU. The exposure times vary based on the radial position of each row. The first and sixth rows hold control samples and are not exposed to the atmosphere.

\begin{tabular}{lr}
\hline Row & Exposure Time [s] \\
\hline 1 & 0.0 \\
2 & 4.0 \\
3 & 1.7 \\
4 & 2.3 \\
5 & 2.7 \\
6 & 0.0 \\
\hline
\end{tabular}

structure. The chemical compositions of the particles are given in Table 2 as spectra 1 and 2.

For the atmospheric test the FFU was loaded with seven sample holders: four TEM grids, one glass fibre filter and two silicone gel probes. The loaded FFU was exposed to the atmosphere at around $90 \mathrm{~km} \mathrm{~h}^{-1}$ on the E4 highway, north of Stockholm on 29 November 2011. During this test the rotating collection plate exposed five samples for $10 \mathrm{~s}$ each. The one control TEM grid that was not exposed to the atmosphere did not show particle contamination. Particles with sizes between $100 \mathrm{~nm}$ and $50 \mu \mathrm{m}$ were found on the glass fibre filter, silicone gel samples and TEM grid. The results of X-ray analysis of these particles are given in Table 2 as spectrum 3 . These particles contained C, O, Si, F and Ca. The mean X-ray analysis spectrum from these particles is given as spectrum 4 in Table 2.

\section{Electronics}

The experiment electronics is split between the FFUs and the RMU. The experiment is fully automated during launch. The ejection of the FFUs is a timed event, and after leaving the rocket the FFUs activate their ACEs, collect sensor data, deploy their parachutes and transmit localization messages based on a predetermined timeline hard-coded in the on-board ProASIC3 Finite Programmable Gate Arrays (FPGAs) from Actel. Each FFU has a main FPGA responsible for monitoring the flight schedule and activating events and a second experiment FPGA that manages ACE control and the collection of raw GPS data.

Each FFU is powered by a Li-ion rechargeable SAFT MP144350 battery, which can be recharged while the FFUs are in the rocket. The nominal capacity of the battery operating at $-30^{\circ} \mathrm{C}$ is $2.25 \mathrm{Ah}$ at a cell voltage of $2.75 \mathrm{~V}$ when drawing 0.5 A (SAFT, 2009), which is sufficient for powering the FFU for $24 \mathrm{~h}$. This has also been proven in FFU thermal tests.
Table 2. Mean results of the X-ray analysis of particles measured during the sampling tests. Spectra 1 and 2 show the mean of two and four individual analyses of particles found after the laboratory test, respectively. Spectra 3 and 4 each show the mean of two X-ray analyses of particles found during the atmospheric test.

\begin{tabular}{lcccccccc}
\hline & $\mathrm{C}$ & $\mathrm{N}$ & $\mathrm{O}$ & $\mathrm{Al}$ & $\mathrm{Cl}$ & $\mathrm{Si}$ & $\mathrm{F}$ & $\mathrm{Ca}$ \\
\hline Spectrum 1 & - & 17 & 58 & 19 & 6 & - & - & - \\
Spectrum 2 & - & - & 27 & 72 & - & - & - & - \\
Spectrum 3 & 83 & - & 17 & - & - & - & - & - \\
Spectrum 4 & 24 & - & 18 & 2 & - & 15 & 32 & 3 \\
\hline
\end{tabular}

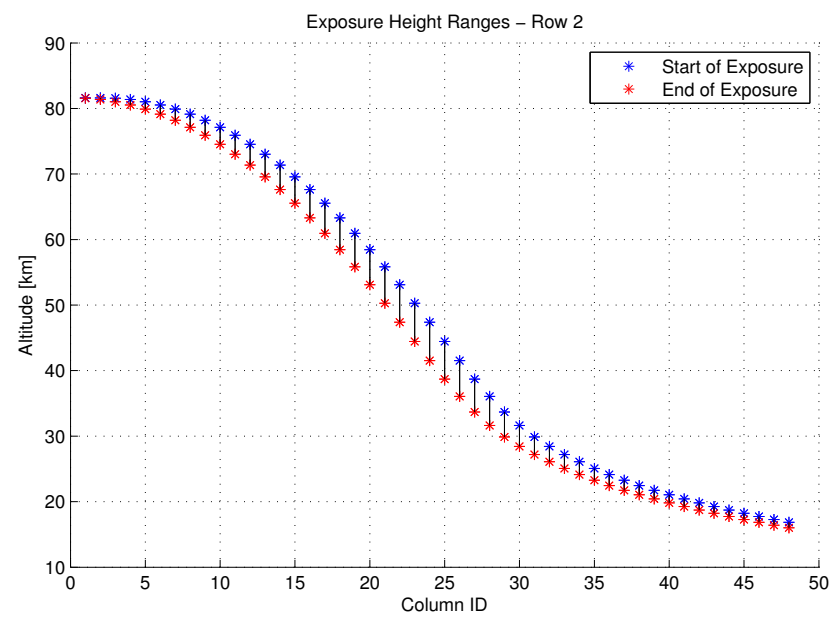

Fig. 8. The height ranges that each of the collection samples in row 2 are exposed to according to a six degrees of freedom simulation of a falling FFU. There are 45 distinct height ranges that samples are exposed to.

Each FFU collects and stores housekeeping and raw GPS data in a non-volatile memory sensor. From the raw GPS data it is possible to extract the position, velocity and acceleration after post-processing. The internal sensors in each FFU are a LIS344ALH 3-axis accelerometer from STMicroelectronics, a LYPR540AH 3-axis angular rate sensor from STMicroelectronics, a MPXH6115A6U pressure sensor from Freescale Semiconductor, an AD590 temperature sensor from Analog Devices and the ACE AM4096D02 angular magnetic encoder from RLS. The sensor outputs are all analog and converted by AD7276 12-bit analog to digital converters (ADCs). A 16-channel multiplexer CD4067B from Texas Instruments rotates ADC input, which is sampled at 4000 samples/second. Thus each channel is sampled at 250 samples/second. The main FPGA packages the ADC data with a timestamp and saves it into a $\operatorname{HY} 27 \mathrm{UF}(08 / 16) 4 \mathrm{G} 2 \mathrm{~B}$ 4 Gbit NAND memory from Hynix.

The raw GPS data are collected using a consumer grade MAX2769 front end from Maxim. An active WS3914 antenna from Wi-Sys Communications provides the signal to the input of the front end, which down converts 
and digitizes the data in a 2-bit sign/magnitude format at $8.192 \mathrm{Msamples} / \mathrm{second}$. The intermediate frequency is set to 1575.42 MHz. The recorded raw data are analysed post-flight using a software GPS receiver and a custom trajectory reconstruction algorithm. The use of raw data recording is in part to circumvent the altitude and speed limitations imposed on commercial GPS modules, and in part to improve the trajectory reconstruction accuracy.

Upon parachute deployment, the localization system is activated. The GPS antenna signal is re-routed by a PE4230 RF switch from Peregrine Semiconductor to an ET-318 commercial GPS module from US Global Sat.

The GPS coordinates are modulated into a radio beacon signal transmitted using the radio beacon antenna. Each FFU transmits this signal on a distinct frequency, either $173.225 \mathrm{MHz}$ or $172.250 \mathrm{MHz}$. The GPS coordinates are also transmitted to the Globalstar satellite network via the satellite modem and antenna.

The RMU houses communication relay circuitry that allows ground controllers to command each FFU and activate the camera on board the RMU, which has a view out the side of the rocket cylinder and captures the entire rocket flight. All communication with the RMU passes through the REXUS service module described in EuroLaunch (2010). Power is supplied to the RMU and FFUs while they are still in the rocket by the rocket's service module's batteries. Ejection of the FFUs is not controlled by RMU circuitry; it is triggered directly by a mechanical timer in the service module.

\section{Conclusions}

The proposed technique is a new method for collecting aerosol particles in the mesosphere and stratosphere that have previously been inaccessible to balloon and sounding rocket aerosol collection experiments. Two spin-stabilized collection probes or FFUs ejected from the sides of a sounding rocket collect aerosol particles between 17 and $85 \mathrm{~km}$. Each FFU incrementally exposes collection samples to the passing atmosphere over 45 separate height ranges.

Three separate types of sample materials are used to collect particles of different size ranges. On the TEM grids it is expected that meteoric smoke particles in the size range between 5 and $10 \mathrm{~nm}$ in the mesosphere and larger than $10 \mathrm{~nm}$ in the stratosphere (Megner et al., 2006, 2008) be sampled. As shown by Hedin et al. (2007a) however, the detection efficiency for meteoric smoke particles in the nanometre size range is very much altitude dependent. Hedin et al. (2007a) also mentioned that below $70-75 \mathrm{~km}$ it is difficult to detect any particles smaller than $5 \mathrm{~nm}$. Particles are expected to be larger at lower altitudes (Megner et al., 2006). It is expected that the larger stratospheric aerosol particles be sampled on the glass fibre and silicone gel.

After collecting aerosols, each FFU broadcasts its GPS position and is recovered by a ground support crew. SEM and
$\mathrm{X}$-ray analysis of each collection sample is performed after recovery. The technique has been proven to not significantly contaminate the collection samples during handling and running of the experiment. The results of the experiment could be used for future design iterations to better collect aerosols in the stratosphere and mesosphere. Furthermore, the collected flight dynamics data could be used for aerodynamics analysis to improve future instruments.

Acknowledgements. We would like to thank the entire RAIN team for their hard work and commitment to the design, implementation and testing of the experiment. Thanks go to the Swedish National Space Board for their support throughout the development of this experiment. Thanks to the Swedish National Space Board and German Aerospace Center for organizing and managing the REXUS project. The department of Space and Plasma Physics and the department of Mechanics at KTH have been invaluable with providing continued help and support. We would also like to acknowledge Kjell Jansson and Sofhia Josborg for their help with the scanning electron microscope analysis.

Edited by: J. Curtius

\section{References}

Bigg, E., Kviz, Z., and Thompson, W.: Electron microscope photographs of extraterrestrial particles, Tellus, 23, 247-260, doi:10.1111/j.2153-3490.1971.tb00567.x, 1971.

Blanchard, M., Ferry, G., and Farlow, N.: Analyses of particles on surfaces exposed to the 1965 Leonid Meteor Shower by the Luster Sounding Rocket, J. Geophys. Res., 73, 6347-3660, doi:10.1029/JA073i019p06347, 1968.

Bourassa, A., Robock, A., Randel, W., Deshler, T., Rieger, L., Lloyd, N., Llewellyn, E., and Degenstein, D.: Large Volcanic Aerosol Load in the Stratosphere Linked to Asian Monsoon Transport, Science, 337, 78-81, 2012.

Bremer, J., Hoffmann, P., Latteck, R., Singer, W., and Zecha, M.: Long-term changes of (polar) mesosphere summer echoes, J. Atmos. Sol.-Terr. Phy., 71, 1571-1576, 2009.

Capannelli, G., Castello, E., Comite, A., Costa, C., and Mamolini, G.: Electron microscopy characterization of airborne micro- and nanoparticulate matter, J. Electron Microsc., 60, 117-131, 2011.

Corte, V. D., Palumbo, P., Rotundi, A., Angelis, S. D., Rietmeijer, F., Bussoletti, E., Ciucci, A., Ferrari, M., Galluzzi, V., and Zona, E.: In Situ Collection of Refractory Dust in the Upper Stratosphere: The DUSTER Facility, Space Sci. Rev., 169, 159-180, doi:10.1007/s11214-012-9918-9, 2012.

DeFoor, J., Robinson, E., and Ryan, S.: Early lidar measurements of the June 1991 Pinatubo eruption plume at Manua Loa Observatory, Geophys. Res. Lett., 19, 187-190, 1992.

DeLand, M., Shettle, E., Thomas, G., and Olivero, J.: A quartercentury of satellite PMC observations, J. Atmos. Sol.-Terr. Phy., 68, 9-29, 2006.

Deshler, T., Hervig, M., Hofmann, D., Rosen, J., and Liley, J.: Thirty years of in situ stratospheric aerosol size distribution measurements from Laramie, Wyoming $\left(41^{\circ} \mathrm{N}\right)$, us- 
ing balloon-borne instruments, J. Geophys. Res., 108, 4167, doi:10.1029/2002JD002514, 2003.

EuroLaunch: REXUS User Manual, Euro Launch, 7.1 Edn., available at: http://www.rexusbexus.net/index.php?option= com_content $\backslash \&$ view=article $\backslash$ \&id=\%47 $\$ \&Itemid=59 (last access: 7 May 2011), 2010.

Farlow, N.: Electron microscope studies of particles on sampling surfaces recovered from space with sounding rockets, J. Geophys. Res., 73, 4363-4371, doi:10.1029/JA073i013p04363, 1968.

Farlow, N., Ferry, G., and Blanchard, M.: Examination of surfaces exposed to a noctilucent cloud, 1 August 1968, J. Geophys. Res., 75, 6736-6750, doi:10.1029/JC075i033p06736, 1970.

Fechtig, H. and Feuerstein, M.: Particle collection results from a rocket flight on August 1, 1968, J. Geophys. Res., 75, 67516757, doi:10.1029/JC075i033p06751, 1970.

Goldberg, R., Pfaff, R., Holzworth, R., Schmidlin, F., Voss, H., Tuzzolino, A., Croskey, C., Mitchell, J., Friedrich, M., Murtagh, D., Witt, G., Gumbel, J., von Zahn, U., Singer, W., and Hoppe, U.: DROPPS: a study of the polar summer mesosphere with rocket, radar and lidar, Geophys. Res. Lett., 28, 1407-1410, 2001.

Gumbel, J.: Atmospheric science with sounding rockets - present status and future perspectives, Proc. 18th ESA Symposium on European Rocket and Balloon Programmes and Related Research, Visby, Sweden, ESA SP-647, 47-54, 2007.

Hamill, P., Jensen, E., Russell, P., and Bauman, J.: The Life Cycle of Stratospheric Aerosol Particles, B. Am. Meteorol. Soc., 78, 1395-1410, 1997.

Havnes, O., Troim, J., Blix, T., Mortensen, W., Naesheim, L., Thrane, E., and Tonnesen, T.: First detection of charged dust in the Earthatmosphere., J. Geophys. Res., 101, 10839-10847, 1996.

Hedin, J., Gumbel, J., and Rapp, M.: On the efficiency of rocketborne particle detection in the mesosphere, Atmos. Chem. Phys., 7, 3701-3711, doi:10.5194/acp-7-3701-2007, 2007a.

Hedin, J., Gumbel, J., Waldemarsson, T., and Giovane, F.: The aerodynamics of the MAGIC meteoric smoke sampler, Adv. Space Res., 40, 818-824, doi:10.1016/j.asr.2007.06.046, 2007b.

Hofmann, D.: Increase in the stratospheric background sulfuric acid aerosol mass in the past 10 years, Science, 248, 996-1000, 1990.

Hofmann, D. and Rosen, J. M.: Stratospheric sulfuric acid layer Evidence for an anthropogenic component, Science, 208, 1368$1370,1980$.

Hofmann, D., Rosen, J. M., Pepin, T. J., and Pinnick, R. G.: Stratospheric aerosol measurements I, Time variations at northern midlatitudes, J. Atmos. Sci., 32, 1446-1456, 1975.

Jager, H.: Long-term record of lidar observations of the stratospheric aerosol layer at Garmisch-Partenkirchen, J. Geophys. Res., 110, D08106, doi:10.1029/2004JD005506, 2005.

Junge, C., Changnon, C., and Manson, J.: A world-wide stratospheric aerosol layer, Science, 133, 1478-1479, 1961.

Kaifler, N., Baumgarten, G., Fiedler, J., Latteck, R., Lübken, F.J., and Rapp, M.: Coincident measurements of PMSE and NLC above ALOMAR $\left(69^{\circ} \mathrm{N}, 16^{\circ} \mathrm{E}\right)$ by radar and lidar from 1999 2008, Atmos. Chem. Phys., 11, 1355-1366, doi:10.5194/acp-111355-2011, 2011.

Kandler, K., Benker, N., Bundke, U., Cuevas, E., Ebert, M., Knippertz, P., Rodriguez, S., and Weinbruch, L. S. S.: Chemical composition and complex refractive index of Saharan Mineral Dust at
Izana, Tenerife (Spain) derived by electron microscopy, Atmos. Environ., 41, 8058-8074, 2007.

Lynch, K. A., Gelinas, L., Kelley, M., Collins, R., Widholm, M., Rau, D., MacDonald, E., Liu, Y., Ulwick, J., and Mace, P.: Multiple sounding rocket observations of charged dust in the polar winter mesosphere, J. Geophys. Res., 110, A03302, doi:10.1029/2004JA010502, 2005.

McCormick, M., Hamill, P., Pepin, T. J., Chu, W. P., Swissler, T. J., and McMaster, L. R.: Satellite studies of the stratospheric aerosol, B.Am. Meteorol. Soc., 60, 1038-1046, 1979.

Megner, L., Rapp, M., and Gumbel, J.: Distribution of meteoric smoke - sensitivity to microphysical properties and atmospheric conditions, Atmos. Chem. Phys., 6, 4415-4426, doi:10.5194/acp-6-4415-2006, 2006.

Megner, L., Siskind, D., Rapp, M., and Gumbel, J.: Global and temporal distribution of meteoric smoke: A two-dimensional simulation study, J. Geophys. Res., 113, doi:10.1029/2007JD009054, 2008.

Osborn, M., DeCoursey, R. J., Trepte, C. R., Winder, D. M., and Woods, D. C.: Evolution of the Pinatubo volcanic cloud over Hampton Virginia, Geophys. Res. Lett., 22, 1101-1104, 1995.

Parungo, F. and Nagamoto, C.: Temporal and spatial variations of marine aerosols over the Atlantic Ocean, Atmos. Res., 20, 23-37, 1986.

Pepin, T., McCormick, M., Chu, W., Simon, F., Swissler, T., Adams, R., Crumbly, K., and Fuller, W.: Stratospheric aerosol measurements, NASA Spec. Publ., SP-421, 127-136, 1997.

Pérot, K., Hauchecorne, A., Montmessin, F., Bertaux, J.-L., Blanot, L., Dalaudier, F., Fussen, D., and Kyrölä, E.: First climatology of polar mesospheric clouds from GOMOS/ENVISAT stellar occultation instrument, Atmos. Chem. Phys., 10, 2723-2735, doi:10.5194/acp-10-2723-2010, 2010.

Plane, J.: The role of sodium bicarbonate in the nucleation of noctilucent clouds, Ann. Geophys., 18, 807-814, 2000, http://www.ann-geophys.net/18/807/2000/.

Poole, L. and Pitts, M. C.: Polar stratospheric cloud climatology based on Stratospheric Aerosol Measurement II observations from 1978 to 1989, J. Geophys. Res., 99, 13083-13089, 1994.

Rapp, M., Hedin, J., Strelnikova, I., Friedrich, M., Gumbel, J., and Lübken, F.-J.: Observations of positively charged nanoparticles in the nighttime polar mesosphere, Geophys. Res. Lett. 32, doi:10.1029/2005GL024676, 2005.

Reissaus, P., Waldemarsson, T., Blum, J., Clement, D., Llamas, I., Mutschke, H., and Giovane, F.: Sticking efficiency of nanoparticles in high-velocity collisions with various target materials, J. Nanopar. Res., 8, 693-703, 2006.

SAFT: Rechargeable Li-ion battery; MP 144350, SAFT, available at: http://www.saftbatteries.com/doc/Documents/liion/Cube572/ MP144350_1009.ff6efb8d-6aab-45ef-ae7a-7fe4af5b011d.pdf (last access: 4 September 2012), 2009.

Sielicki, P., Janik, H., Guzman, A., and Namiesnik, J.: The Progress in Electron Microscopy Studies of Particulate Matters to Be Used as a Standard Monitoring Method for Air Dust Pollution, Crc. Cr. Rev. Anal. Chem., 41, 314-334, 2011.

Smiley, B., Rapp, M., Blix, T., Robertson, S., Horanyi, M., Latteck, R., and Fiedler, J.: Charge and size distribution of mesospheric aerosol particles measured inside NLC and PMSE during MIDAS MaCWAVE, J. Atmos. Sol.-Terr. Phy., 68, 114-123, 2002. 
Soberman, R. and Hemenway, C.: Meteoric dust in the upper atmosphere, J. Geophys. Res., 70, 4946-4949, doi:10.1029/JZ070i019p04943, 1965.

Solomon, S., Daniel, J. S., Neely III, R. R., Vernier, J.-P., Dutton, E. G., and Thomason, L. W.: The Persistently Variable Background Stratospheric Aerosol Layer and Global Climate Change, Science, 333, 886-870, 2011.

Summers, M. E. and Siskind, D. E.: Surface recombination of O and $\mathrm{H}_{2}$ on meteoric dust as a source of mesospheric water vapor, Geophys. Res. Lett., 26, 1837-1840, 1999.

Testa, J., Stephens, J., Berg, W., Cahill, T., Onaka, T., Nakada, Y., Arnold, J., Fong, N., and Sperry, P.: Collection of microparticles at high balloon altitudes in the stratosphere, Earth Planetray Si. Lett., 98, 287-286, 1990.
Thomason, L. W., Poole, L. R., and Randall, C. E.: SAGE III aerosol extinction validation in the Arctic winter: comparisons with SAGE II and POAM III, Atmos. Chem. Phys., 7, 14231433, doi:10.5194/acp-7-1423-2007, 2007.

Turco, R., Toon, O., Whitten, R., Keesee, R., and Hollenbach, D.: Noctilucent clouds: Simulation studies of their genesis, properties and global influences, Planet. Space Sci., 3, 1147-1181, 1982. 